\title{
The Influence of Purchase batch on Wholesale Pricing Strategy Selection on B2B Platform
}

\author{
Siyu Chen ${ }^{1, \mathrm{a}}$,Tianyang $\operatorname{Lou}^{2, \mathrm{~b}}$ \\ ${ }^{1}$ Zhejiang Gongshang University, Hangzhou, Zhejiang, China \\ ${ }^{2}$ Zhejiang Gongshang University, Hangzhou, Zhejiang, China \\ a328390877@qq.com \\ bloutianyang@zjgsu.edu.cn
}

\begin{abstract}
In recent years, there are more and more online purchasing platforms, manufacturers as a seller in B2B platform release products by a wide variety of wholesale pricing strategies, such as: member price, stepwise pricing, bundling pricing, and so on. The same product may appear at two different prices in two stores, but the buyer pays the same price to get the product. In this paper, the different batch requirements of purchasers are taken as independent variables, and the pricing strategy of oneprice and the stepwise pricing strategy are taken as dependent variables. According to the data collected by the experiment, the following conclusions are verified: purchase batch will affect the selection of pricing strategy by purchasers, and price equity perceives the influence of intermediary wholesale batch on wholesale pricing strategy. Product types play a moderating role in purchasing batch and price equity perception.
\end{abstract}

Keywords-B2B platform; Wholesale pricing strategy; Price equity perception; Purchase Batch

\section{INTRODUCTION}

B2B electronic market as the birth of the earliest ecommerce mode, is back in the development of e-commerce, according to iresearch data show that in 2015, the constituents of the e-commerce market segmentation industry more than small and medium-sized enterprises and the scale of enterprise $\mathrm{B} 2 \mathrm{~B}$ e-commerce model of the whole industry has close to $70 \%$ market share, $\mathrm{B} 2 \mathrm{~B}$ e-commerce is still the mainstream in the market (iresearch, 2016) [1]. On the other hand, according to iresearch consulting (2016) in 2015, the Chinese ecommerce data survey, in 2015, our country small and medium-sized enterprise B2B e-commerce operation platform scale has reached 21.59 billion yuan, revenue growth rate of $14.6 \%$.Data shows the B2B model in e-commerce development situation is good, in this mode is advantageous to the professional market to find suitable for the development of the enterprise electronic commerce model so as to transform and upgrade to complete (Grieger, 2003). Therefore, many analysts believe that $\mathrm{B} 2 \mathrm{~B}$ e-commerce market will dominate the future development of e-commerce (Xiongwen Lu, et al., 2008) [9]. Due to the continuous development of B2B platform and increase, provide a place to wholesalers purchase products more and more, according to statistics, in Paris in the autumn of 2016 SEC buyers have 83507 people, $97 \%$ of buyers in purchasing online or ask price. The presentation of price is the most intuitive and obvious sign for purchasers who adopt online purchasing. Nowadays, the e-commerce market is in full bloom, and the pattern update and iteration are changing with each passing day: B2B, B2C, C2C, comprehensive, vertical, etc. Pattern diversity, however, is not like retailing bring development cycle (Wang Xuekai, 2018), but more linger in how strong shearing section.at the mode, constantly looking for blank area of the market, rather than the reverse circulation of the entire e-commerce industry. Alibaba is the world's largest, internet-based international trade exchange market supply and demand, to provide from the global 178 countries (regions) of the latest business opportunities with rapid development of information and a merchant community, according to the CNNIC network marketing business brand analysis report, you can see that alibaba is still as the network marketing, ecommerce leader on (CNNIC, 2018). Since 2013, Alibaba has been shifting its strategic focus to B2B business, trying to shift its $\mathrm{B} 2 \mathrm{~B}$ business model from an information platform to a trading platform. There is a huge blue ocean space.This paper will take the trading mechanism of alibaba platform as the research background to show the status of trading mechanism of B2B platform. A growing number of B2B vertical electronic markets have online trading capabilities that allow buyers and sellers to trade online. Because with wholesalers, presenting methods B2B electronic market in the seller's price is different in price way, such as taobao is also different from the auction, many businesses have adopted ladder pricing methods. The design of the wholesale pricing mechanism is essentially a discount system for buyers of different purchasing scale on B2B platform. In the past, a lot of literature perspectives on price have been put on end consumers, mainly is the study of the form, differential pricing, time limited promotion price discount, However, there is little research on the wholesale pricing strategy of $\mathrm{B} 2 \mathrm{~B}$ platforms. Different expressions of price discount will affect consumers' processing of discount promotion information, thus influencing the effect of promotion $(\mathrm{Hu}$, Parsa \& Khan, 2006, Liaogang Hao, et al., 2008). Some studies have found that differential pricing can affect enterprise performance (Sousa and Bradley, 2008), consumer respect (Grewal et al., 2012) and price equity perception (Hinz et al., 2011) [5]. This study is based on the nation's largest Alibaba B2B procurement platform as the research object, the paper mainly discusses the purchaser of B2B electronic market platform for wholesale pricing preference choice, and this choice is affected by other variables Specifically speaking: (1) is there any significant difference 
between the buyer's wholesale price of suppliers and the stepwise price of suppliers? (2) whether the purchasing agent will influence the purchasing agent's choice of wholesale pricing form strategy under different purchasing batch situations and different product types; (3) what is the mechanism by which the purchaser chooses a particular form of wholesale pricing?

\section{LITERATURE REVIEW AND RESEARCH HYPOTHESIS}

\section{A. Wholesale pricing strategy on B2B electronic market platform}

The emergence of B2B electronic market model meets the needs of enterprises' trading mechanism in virtual space. B2B electronic market as matching buyers and sellers, convenient online trading intermediary between them, it provides a potentially huge interests, both of the buyer with the help of a B2B electronic market can reduce procurement costs a lot, the seller may further expand the customer base, hitting a new profit customers. In western theories of price discrimination, according to Pigou (Pigou), general studies divide price discrimination into three types, which are defined as first, second and third price discrimination respectively. For different consumers to sell the same product in different price, can be divided into three levels: the level of price discrimination, is a manufacturer of every unit of goods sold by consumers willing to pay the highest price, type of pricing by buyout price in B2B platform to present; Secondary price discrimination, which only requires different prices for different consumption quantities, is presented as secondary price in B2B platform. Level 3 price discrimination, that is, monopoly manufacturers charge different prices for the same product in different markets (or different consumer groups), and it is presented in the B2B platform with stepwise pricing. Traditional environment suppliers tend to be faced with multiple buyers, thus some scholars composed of more than a suppliers and buyers sales channels are studied, Chen et al. (2001) from the year sales batch discounts, bulk discount and order frequency discount from three aspects, separately for each purchaser to establish different wholesale price; Wang et al. (2005) formulated corresponding quantity discount policies for different price-sensitive retailers, Domestic scholar Chen and Liu (2008)[7] demand function is constructed in the same price the retailer scenario as a single wholesale price model of the product bought from the vendor, and was used to solve the optimal wholesale price. The three-level pricing on B2B platforms is a kind of differential pricing, which will affect enterprise performance (Sousa and Bradley, 2008), consumer respect (Grewal et al., 2012)[10] and price equity perception (Hinz et al., 2011)[5].On B2B electronic market platform, there are both one price and step pricing. The so-called one price is a single price, and the stepwise pricing is a non-linear pricing strategy according to the purchase amount (wei zhonglong, guo Chen, 2007).We think the purchaser in the face of different way of rendering the same prices, although is the same purchase price, because of the existence of price reference factor, so affect product's perceived value judgment, which affect their purchase intention.

\section{B. Factors influencing the purchaser's choice of the wholesale price}

Kahneman and Tversky (1979)'s prospect theory provides theoretical support for the explanation of frame effect. They believe that decision makers' choices are divided into two stages under risk conditions: editing stage and evaluation stage. In the editing stage, there are mainly a series of information processing such as the code, combination, decomposition and clipping of decision makers. In the evaluation stage, according to the value function of decision maker, the maximum expected utility is the final choice of decision making. The key in the framework of prospect theory is the subjective value function, because its value function will have a valuable reference point (zhao lijun, 2010). Heath, etc. (1995), mental account theory to help decision makers the application can be extended to multiple attribute decision-making things pricing strategy, prove that the algorithm of mental accounts, consumer perception of price and reference point depends on reference point setting "framework", namely the description of the reference point setting, there is a clear relationship. Studies of consumer behavior, points out that consumer price comparison when shopping is a very natural thing (Monroe, 2003), when consumers perceive they pay the price and the price of the in the mind have not at the same time, the comparison will appear: Reference price (for example, consumers get price reference points, so their perception will be affected by their expected cost of the seller), competitive prices and businesses use the strategy of market price, other prices paid by consumers or other sellers selling price (2006, Bolton and Alba)[6] in the face of different batch correspond to different prices, purchasing chamber of commerce in found in prices, want to achieve as the reference point, the price of the reference point may lead to higher price (UN) fairness perceptions, may also result in a higher sense of injustice. This study the purchase batch is divided into three categories: large batch, medium batch, small batch, according to its own bulk buyers demand will look for the appropriate price, if it is a large batch demand, according to the theory frame, in the face of ladder pricing on minimum batch requirement will correspond to the highest price, the greater the batch request corresponding to the lower price, so the purchasing chamber of commerce more clearly that he had enjoyed the lowest wholesale price, this will increase the price of the buyers to a sense of fairness perception, so as to promote the realization of purchase intention; If it is small batch purchase demand, in the face of ladder pricing method according to the theory of frame will think by price discrimination, so buyers in the case of small batch demand will tend to choose wholesale price of pricing strategy. In batch purchasing requisition, if in the face of ladder pricing, though not enjoy the large of the lowest price, but because there is a clear reference point, prices lower than the lowest wholesale prices, realize that this is a fair price; If it is one-stop pricing, it is still inclined to choose a tiered pricing method because it is not sure whether the corresponding wholesale pricing discount is available. Therefore, different batches will lead to different wholesale pricing strategies for buyers to choose. Based on this, hypothesis 1 is proposed in this paper: 
H1: Different purchase quantities have different effects on the purchasing agent's choice of wholesale pricing strategy.

\section{The mediating role of price equity perception}

Fairness is a belief in results, processes and interactive justice (Bolton et al., 2013). Price equity is consumers' perception and judgment of price justice, legality and rationality (Campbell, 2007) [3]. Price (UN) fairness perceptions is defined like this: a consumer's evaluation and emotion, and the feelings of the seller's price is different from other competitors, if the price is reasonable, acceptable, or is fair (Xia et al., 2004)[2].Some scholars such as Namkung and Jang (2010) will be defined as: fair price according to the current price and standard (reference price), and the interests of the individual by society (level adjusting) decision acceptable price comparison, the consumer to make overall evaluation. Maxwell et al. (2009) [8] pointed out that price equity occurs only when a reasonable and fair price is fixed. Sometimes consumers think the price is fair because the price is lower than they expect. Price a sense of fairness tells the influence on consumers' perceived value and purchase intention, satisfaction, loyalty, and complain, etc., when the consumer think the price is not fair, they tend to reduce the purchase intention, complain, or even negative word of mouth (Xia et al., 2004). Once consumers decide that the pricing strategy is fair, as such price is also considered fair (Haws and Bearden, 2006). Fair perception of price setting process and the use of certain pricing strategies will influence consumers' perception of price fairness, consumers' attitude towards merchants and consumers' purchase intention (Garbarino and Maxwell,2010)[4].Information in the Internet age, the price is more transparent, consumers can through the online search engine to collect a lot of valuable information or price comparison website (Bock, etc., 2007), it is easier to learn the product price (Simon and Schumann, 2001), purchaser before purchasing behavior on the B2B platform easier to obtain information about the price. When suppliers in the $\mathrm{B} 2 \mathrm{~B}$ platform set different prices in the shop after form, combined with his purchase batch calculation and consideration, the purchase price is get enough discount, the price is fair enough. Based on this, hypothesis 2 is proposed in this paper:

H2: Price equity perception mediates the relationship between purchase batch and wholesale pricing strategy.

\section{The adjusting role of product type}

Clue theory refers to a series of clues that have been passed on to indicate the quality of products to consumers, and consumers use these clues to judge the quality of products (wang xinxin and Yang defeng, 2007).Based on the theory of clue utilization, Olson and Jacoby (1972) divided the clues into external clues and internal clues. The external clue is related to the external attributes of the product, such as related price, brand name, etc. Internal clues are inherent characteristics of a product such as its ingredients, taste, and touch. However, sometimes it is impossible for consumers to judge product quality through some internal clues because they cannot directly contact with products. If internal cues are missing or cannot be processed, consumers are more likely to use external cues to evaluate product quality (Miyazaki, 2005). It is more meaningful to study the influence of external clues on consumers' purchasing intention in the network environment than to study internal clues. The research in this paper mainly focuses on household goods. The product categories are: highvalue products and low-value products. The two obvious price differences form an external clue. In the relationship between price and quality, consumers often judge product quality by price. Especially in the uncertain environment where there is no other attribute reference, consumers often believe that high price will bring high quality products. In present stepwise wholesale pricing, the price of the ladder, the ladder range distribution of high prices often higher than the low price range, the steps of the awareness to save with the prominence of price discount increase (Krishna, 2002),As a result, the greater the demand for batch, the more sensitive consumers are too high prices. In the face of high price products, large quantities will lead buyers to obtain higher price equity perception when choosing step wholesale pricing strategy. The smaller the demand for batch is, the more likely consumers are to have the mentality of being close to retail, the smaller the demand for price is, and the easier it is to get a sense of fairness. In the face of low price products, compared with the stimulation of high price, small batch will make purchasers more likely to have higher price equity perception. Based on this, hypothesis 3 is proposed in this paper:

H3: Product types are adjusted for the impact of purchase batch on price equity perception

H3a: Under the high-value product type, compared with the medium batch and small batch, the buyer gets a greater sense of price equity.

$\mathrm{H} 3 \mathrm{~b}$ : Under low-value product types, medium batch and small batch are more likely to gain a better sense of price equity than large quantities.

The research model constructed in this paper is shown as the following figure: 


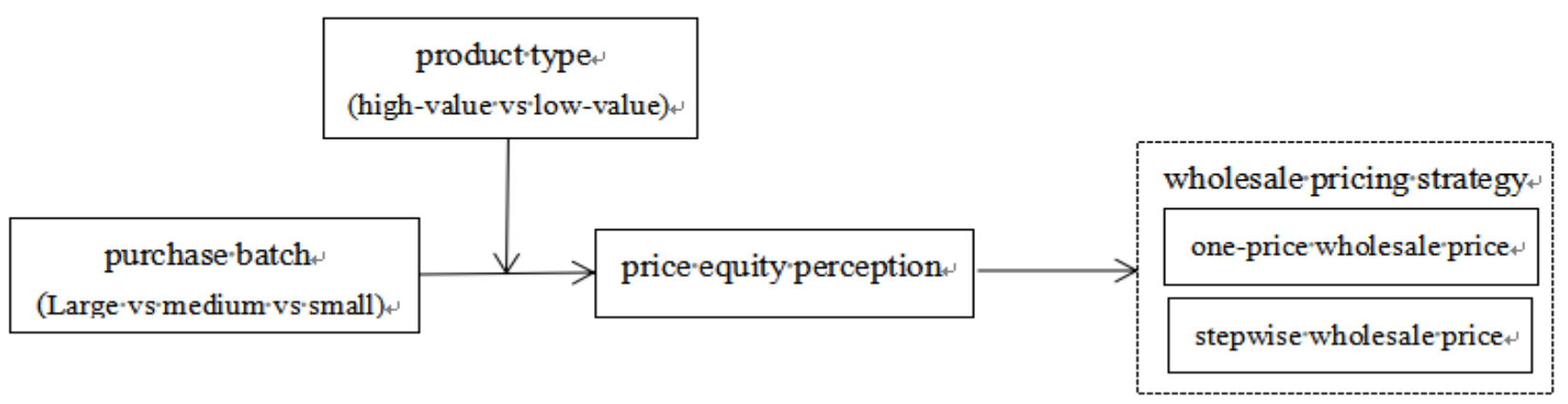

Fig. 1. research model

\section{RESEARCH AND DESIGN}

In this study, situational experiments were used. To investigate the influence of $\mathrm{B} 2 \mathrm{~B}$ platform purchase batch on the choice of wholesale pricing strategy, and the effect of product type on price equity perception of purchase batch on the adjustment of purchase batch, so as to influence the selection of wholesale pricing strategy.

\section{A. Experimental methods and procedures}

Participants in the experiment were 158 students from a comprehensive university in zhejiang province, and 148 students completed the experiment, $70.2 \%$ of whom were women. In this experiment, 3(purchase batch: large batch vs. medium batch vs. small batch) $* 2$ (product type: high value product vs. low value product) was adopted for the intergroup experiment design. This experiment takes on alibaba platform keep-warm glass as the research object, the experimental materials from alibaba platform to select two different cups worth of online wholesale images, to a certain change, simulation on alibaba platform online wholesale page. Participants were randomly assigned into six groups, first of all tell participants hypothesis is now going to wholesale glass on alibaba B2B platform, tell the number of participants need wholesale, and then give the same products, but pictures of two different pricing ways, through the pictures show, were then asked to try after looking at two wholesale pricing present willing to choose which kind of pricing method.

TABLE I. DESCRIPTIVE STATISTICS OF PURCHASE BATCH OF PRODUCT TYPE GROUPING

\begin{tabular}{|c|c|c|c|c|c|}
\hline \multicolumn{3}{|c|}{ High value set } & \multicolumn{3}{|c|}{ Low value set } \\
\hline $\begin{array}{l}\text { Large } \\
\text { batch }\end{array}$ & $\begin{array}{c}\text { Medium } \\
\text { batch }\end{array}$ & Small batch & Large batch & $\begin{array}{l}\text { Medium } \\
\text { batch }\end{array}$ & $\begin{array}{l}\text { Small } \\
\text { batch }\end{array}$ \\
\hline 23 & 23 & 23 & 28 & 28 & 22 \\
\hline
\end{tabular}

This study measured item price (UN) fairness perceptions from Xia (2010), such as using three item measurement, adopt the likert scale seven $(1=$ strongly disagree, $7=$ completely agree) were measured on perceived price (UN) fairness.

\section{B. Manipulation of the inspection}

Use independent sample t-test to manipulate PiFaLiang two two inspection, inspection, according to the results of PiFaLiang in the classification of large, medium and small successful manipulation (small batch and medium batch: $\mathrm{F}=$ $0.465, \mathrm{~T}=5.521, \mathrm{P}<0.05 ;$ Small batch and large large: $\mathrm{F}=0.703, \mathrm{t}=-8.030, \mathrm{P}<0.05$; Medium batch and large large: $\mathrm{F}=1.901, \mathrm{t}=-2.972, \mathrm{P}<0.05)$.

Using independent sample $\mathrm{T}$ test to control the product type test, test results showed that there were significant differences, explain product type in high and low value on the two classification control success (high value and low value: $\mathrm{F}=$ 5.253, $\mathrm{T}=4.878, \mathrm{P}<0.05)$.

\section{The experimental results}

For the test of hypothesis 1, this paper believes that different purchase batches have different effects on the purchasers' choice of wholesale pricing strategy. First has carried on the dummy variable Settings, to purchase in bulk produced two dummy variables (dummy variable: D1, D2 = = small batch and other medium batch and other), and then to purchase in bulk and wholesale pricing strategy for the logistic binary regression analysis and test results show that the small batch and large statistical differences for wholesale pricing strategy choice $(\mathrm{D} 1: \mathrm{B}=1.807$, sig $=0.000)$, medium batch and large batch's statistical differences for wholesale pricing strategy choice $(\mathrm{D} 2: \mathrm{B}=0.902$, sig $=0.038)$. Therefore, there is a significant difference in the impact of different purchase 
batches on the purchasers' choice of wholesale pricing strategy, that is, supporting $\mathrm{H} 1$.

Tests for the assumption 2, this paper argues that the price (UN) fairness perceptions on the relationship between the purchasing in bulk and wholesale pricing strategy plays a role of intermediary, intermediary function test price (UN) fairness perceptions by regression method. First to return to purchase batch of price (UN) fairness perceptions, inspection, according to the results of small batch and large batch's statistical differences on perceived price (UN) fairness (D1: $\mathrm{B}=0.400, \mathrm{t}$ $=0.400$, sig $=0.032<0.05)$, medium batch and large batch's statistical differences on perceived price (UN) fairness (D2: B $=0.465, \mathrm{t}=0.465, \mathrm{sig}=0.011<0.05)$, so, the purchase large has significant effect on perceived price (UN) fairness. And then to purchase in bulk and wholesale pricing strategy for Logistic, perceived price (UN) fairness binary regression, test results show that the role of price (UN) fairness perceptions for wholesale pricing strategy is significant $(B=1.647$, sig $=1.647$ $<0.05$ ), and purchase in bulk for wholesale pricing strategy is significant $(\mathrm{D} 1: \mathrm{B}=3.113$, sig $=3.113<0.05$. $\mathrm{D} 2: \mathrm{B}=1.874$, sig $=0.003<0.05)$, so. Price equity perception has a significant mediating effect on purchasing batch and wholesale pricing strategy, that is, supporting $\mathrm{H} 2$.
For the test of hypothesis 3, this paper believes that product type adjustment is based on the effect of purchase batch adjustment on price equity perception, and product type adjustment effect test is completed by variance analysis. Small batch and large effect on perceived price (UN) fairness exists significant difference $(p=0.028<0.05)$, medium batch and large batch influence on perceived price (UN) fairness exists significant difference $(\mathrm{p}=0.009<0.05)$, small batch and medium batch to the influence of price (UN) fairness perceptions do not exist significant difference $(\mathrm{p}=0.721>$ $0.05)$, purchase batch of price (UN) fairness perceptions affect significantly $(\mathrm{F}=3.257, \mathrm{p}=0.041<0.05)$. Product type (high value product, low value product) has no significant influence on price equity perception $(\mathrm{F}=0.066, \mathrm{p}=0.797>0.05)$. From figure 1 , it can be seen that under low-value product types $(\mathrm{M}=$ low value), small and medium batches are more likely to gain a better price equity perception than large quantities. In the highvalue product type ( $\mathrm{M}=$ high value), compared with the small batch and medium batch, the buyer gets a greater sense of price equity. The horizontal interaction terms between purchase batch and product type have a significant effect on price equity perception $(\mathrm{F}=5.695, \mathrm{p}=0.004<0.05)$. Therefore, the product type adjustment effect exists, that is, $\mathrm{H} 3$ support.

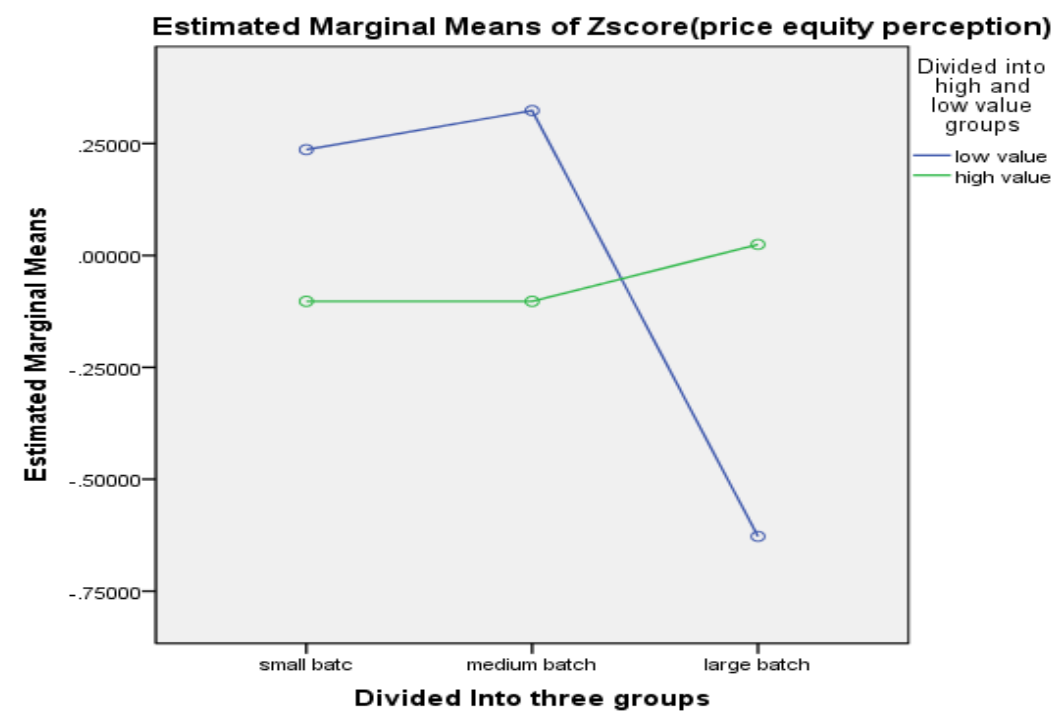

Fig. 2. Adjusting role of product type

\section{RESEARCH CONCLUSIONS AND MANAGEMENT IMPLICATIONS}

The research conclusion of this paper mainly includes three aspects: first, the different purchase batch will affect the buyer's choice of wholesale pricing strategy. In the case of large batch, medium batch and small batch respectively, different choices are made between one-price wholesale pricing strategy and stepwise wholesale pricing strategy. When the bulk demand of purchasers is medium and large batch, purchasers are more inclined to choose the step wholesale pricing strategy. When the bulk demand of purchasers is small, purchasers are more inclined to choose a one-price wholesale pricing strategy. Second, product types play a moderating role in the relationship between purchase batch and price equity perception. Under the high-value product type, compared with the medium batch and small batch, the buyer gets a greater sense of price fairness. Under low value product types, medium batche and small batch are more likely to gain a better sense of price equity than large quantities. Third, price equity perception plays a mediating role in the relationship between purchase batch and wholesale pricing strategy, and explains the mechanism of how purchase batch plays a role in how buyers choose wholesale pricing strategy.

Management implications of this study: firstly, more perfect wholesale pricing strategies are formulated according to the customer types of enterprises (large batch purchasers, medium batch purchasers and small batch purchasers).Stepwise wholesale pricing and price wholesale pricing strategy is a B2B 
online purchase often use pricing strategy, along with the market price is more and more transparent, consumers have a clear pricing differences between regions, enterprises can according to the positioning of the consumer groups, to develop more in line with their purchase bulk pricing strategy, for example, large quantities of buyers are more likely to select stepwise wholesale pricing strategy; Small-batch buyers are more likely to choose a one-price wholesale pricing strategy. Second, under different product types, enterprises can predict consumers' response to wholesale pricing strategies. Under the high-value product type, compared with the medium batch and small batch, the buyer gets a greater sense of price fairness. Under low value product types, medium batch and small batch are more likely to gain a better sense of price equity than large quantities. The greater the price equity perception, the more likely it is to lead to the purchase intention, and thus the more likely it is to choose the wholesale pricing strategy. Enterprises formulate corresponding wholesale pricing strategies according to the characteristics of their own products to enhance the impact of purchase batch on price equity perception.

In addition, this study is aimed at B2B platform trading mechanism of articles for daily use, in the B2B platform for making a deal to purchase bulk purchasing chamber of commerce has a psychological expectations, this also applies to other types of products, and this article does not consider other product type on the platform of the trading mechanism, such as parts, textiles, etc. Second, the subjects of this paper is to college students, while this group of people have a certain knowledge of $\mathrm{B} 2 \mathrm{~B}$ shopping, on the choice of test pricing presentation on online price sensitivity exists, but, after all, not real $\mathrm{B}$ end purchaser for $\mathrm{B} 2 \mathrm{~B}$ trading mechanism is still not known, hope that the future can more expanded empirically more accurate sample groups. Finally, in this paper, the results of the variable for the purchaser's choice of two kinds of wholesale pricing strategy, but also an in-depth research on outcome variables, buyers in purchasing behavior when there is a general purchasing in bulk, but when he saw the present stepwise pricing, will receive gradient prices to stimulate and increase or reduce the purchase quantity, it is also the future study in the direction of the B2B wholesale pricing strategy can further consider.

\section{REFERENCES}

[1] Iresearch consulting. 2015 China e-commerce data release research report [R]. Beijing: iresearch consulting, 2016. (In Chinese)

[2] Xia, L. Monroe, K. B., \& Cox,J. L. The price is unfair! A conceptual framework of price fairness perceptions[J]. Journal of Marketing, 2004, 68(3): 1-15.

[3] Campbell, M.C. "Says Who?!" How the Source of Price Information and Affect Influence Perceived Price (Un)fairness[J]. Journal of Marketing Research, 2007, 44(2): 261-271.

[4] S Maxwell, E Garbarino. The identification of social norms of price discrimination on the internet[J]. Jsme Meeting, 2010, 2004(3): 454-461.

[5] Hinz O, Hann I H, Spann M. Price Discrimination in E-Commerce? An Examination of Dynamic Pricing in Name-Your-Own Price Markets[J]. MisQuarterly, 2011, 35 (1): 81-98.

[6] Bolton, L. E., \& Alba, J. W. Price fairness: Good and service differences and the role of vendor costs[J]. Journal of Consumer Research, 2006(33): 258-265.

[7] Daoping Chen, Wei Liu. Primary distribution channels consisting of one manufacturer and multiple distributors $[\mathrm{J}]$. Systems engineering theory and practice, 2008,12 (3): 36-41. (In Chinese)

[8] Maxwell S., Lee, S., Anselstetter,S. and Comer, L.B. "Gender differences in the perception of unfairness in pricing: a cross-country analysis"[J]. Journal of Consumer Marketing, 2009: 508-515.

[9] Xiongwen Lu, Tianyang Lou,Jun Yan. On the model, value appeal and strategic approach of B2B electronic market[J]. Research and development management, 2008,20 (06) : 23-29. (In Chinese)

[10] Grewal D, Roggeveen A L, Compeau LD, et al. Retail Value-Based Pricing Strategies:New Times, New Technologies, New Consumers [J]. Journal of Retailing, 2012, 88 (1): 1-6. 